\title{
Rocks of different mineralogy show different temperature characteristics: Implications for biodiversity on rocky seashores
}

\author{
Nathan Janetzki ${ }^{\text {Corresp., } 1}{ }^{,}$, Kirsten Benkendorff ${ }^{2}$, Peter G Fairweather ${ }^{1}$ \\ ${ }^{1}$ College of Science \& Engineering, Flinders University, Adelaide, South Australia, Australia \\ 2 Marine Ecology Research Centre, School of Environment, Science and Engineering, Southern Cross University, Lismore, New South Wales, Australia, \\ Lismore, New South Wales, Australia \\ Corresponding Author: Nathan Janetzki \\ Email address: jane0017@flinders.edu.au
}

As some intertidal biota presently live near their upper tolerable thermal limits when emersed, predicted hotter temperatures and an increased frequency of extreme-heat events associated with global climate change may challenge the survival and persistence of such species. To predict the biological ramifications of climate change on rocky seashores, ecologists have collected baseline rock temperature data, which has shown substrate temperature is heterogenous in the rocky intertidal zone. A multitude of factors may affect rock temperature, although the potential roles of boulder surface (upper versus lower), lithology (rock type) and minerology have been largely neglected to date. Consequently, a common-garden experiment using intertidal boulders of six rock types tested whether temperature characteristics differed among rock types, boulder surfaces, and whether temperature characteristics were associated with rock mineralogy. The temperature of the upper and lower surfaces of all six rock types was heterogeneous at the millimetre to centimetre scale. Three qualitative patterns of temperature difference were identified on boulder surfaces: gradients; mosaics; and limited heterogeneity. The frequency of occurrence of these temperature patterns was heavily influenced by cloud cover. Upper surfaces were generally hotter than lower surfaces, plus purple siltstone and grey siltstone consistently had the hottest temperatures and white limestone and quartzite the coolest. Each rock type had unique mineralogy, with maximum temperatures correlated with the highest metallic oxide and trace metal content of rocks. These baseline data show that rock type, boulder surface and mineralogy all contribute to patterns of heterogenous substrate temperature, with the geological history of rocky seashores therefore potentially influencing the future fate of species and populations under various climate change scenarios. 
Rocks of different mineralogy show different temperature characteristics: implications for biodiversity on rocky seashores

\section{Nathan Janetzki ${ }^{1 *}$, Kirsten Benkendorff ${ }^{2}$, Peter G. Fairweather ${ }^{1}$}

${ }^{1}$ College of Science and Engineering, Flinders University, Adelaide, South Australia 5001, Australia

${ }^{2}$ Marine Ecology Research Centre, School of Environment, Science and Engineering, Southern Cross University, Lismore, New South Wales 2480, Australia

* Corresponding author

Postal address: College of Science and Engineering, Flinders University, GPO Box 2100, Adelaide, South Australia 5001, Australia.

Nathan Janetzki email address: nathan.janetzki@outlook.com

Kirsten Benkendorff email address: kirsten.benkendorff@scu.edu.au

\section{Abstract}

2 As some intertidal biota presently live near their upper tolerable thermal limits when emersed,

3 predicted hotter temperatures and an increased frequency of extreme-heat events associated

4 with global climate change may challenge the survival and persistence of such species. To

5 predict the biological ramifications of climate change on rocky seashores, ecologists have

6 collected baseline rock temperature data, which has shown substrate temperature is 
7 heterogenous in the rocky intertidal zone. A multitude of factors may affect rock temperature,

8 although the potential roles of boulder surface (upper versus lower), lithology (rock type) and

9 minerology have been largely neglected to date. Consequently, a common-garden experiment

10 using intertidal boulders of six rock types tested whether temperature characteristics differed

11 among rock types, boulder surfaces, and whether temperature characteristics were associated

12 with rock mineralogy. The temperature of the upper and lower surfaces of all six rock types was

13 heterogeneous at the millimetre to centimetre scale. Three qualitative patterns of temperature

14 difference were identified on boulder surfaces: gradients; mosaics; and limited heterogeneity.

15 The frequency of occurrence of these temperature patterns was heavily influenced by cloud

cover. Upper surfaces were generally hotter than lower surfaces, plus purple siltstone and grey

17 siltstone consistently had the hottest temperatures and white limestone and quartzite the

coolest. Each rock type had unique mineralogy, with maximum temperatures correlated with

the highest metallic oxide and trace metal content of rocks. These baseline data show that rock

type, boulder surface and mineralogy all contribute to patterns of heterogenous substrate

temperature, with the geological history of rocky seashores therefore potentially influencing the future fate of species and populations under various climate change scenarios.

\subsection{Introduction}

Rocky seashores are one of the most thermally-variable and stressful habitats on Earth. Rocky

seashore substrata exposed to insolation can warm by as much as $10-20^{\circ} \mathrm{C}$ while emersed 
ectotherms (i.e. animals) that use rocky seashores as habitat (Connell 1972; Bertness 1999),

which may challenge the survival and ultimately the persistence of some intertidal species.

Examples of the impacts of heat stress on intertidal species include mass-mortality events

during heatwaves (Helmuth et al. 2002; Harley 2008; Seuront et al. 2019), lower survival rates

in thermally less-favourable habitats (Jones and Boulding 1999; Harley 2008; Gedan et al. 2011;

Lathlean et al. 2013; Leal et al. 2020), and restricted vertical seashore distributions of some species (Raimondi 1988; Somero 2002; Harley 2003).

In response to these deleterious impacts from exposure to extreme heat, mobile intertidal ectotherms can employ behavioural thermoregulation and/or morphological adaptations to minimise the risks posed by desiccation and heat stress (Pörtner and Farrell 2008). One mode of behavioural thermoregulation involves retreating to the underside of boulders at low tide (Chapman 2003; Chapperon and Seuront 2011a). Boulder lower surfaces are sheltered from insolation and thus are purported to provide a cooler and more thermally-stable habitat, relative to their thickness (Huey et al. 1989), in comparison to sun-exposed boulder upper surfaces (Chapman 2003; Chapperon and Seuront 2011a; Aguilera et al. 2019). In the rocky intertidal zone, surprisingly few studies have quantified the temperature characteristics of upper versus lower boulder surfaces, with most studies instead quantifying the temperature characteristics of various sun-exposed versus sun-protected habitats (e.g. Garrity 1984; Denny et al. 2011; Chapperon et al. 2017). It is therefore difficult to ascertain from the published literature the actual magnitude of temperature difference that may exist between the tops and bottoms of boulders. 
52 With predictions of hotter air temperatures and an increased frequency of extreme-heat events

53

54

55

56

57

58

59

60

61

62

63

64

65

66

67

68

69

70

71

72

\section{3}

associated with global climate change (IPCC 2013), the survival and persistence of some

intertidal species is likely to be challenged further. To predict the future fate of species and populations, ecologists have collected baseline rock temperature data (Helmuth 1999; Denny et al. 2011; Judge et al. 2011; Gunderson et al. 2019), created heat budget models (Helmuth 1999; Choi et al. 2019), investigated how $x$ species is affected by $y$ substrate temperature (Raimondi 1988; Lathlean et al. 2012; 2013; Lamb et al. 2014), or used biomimetic loggers to investigate how internal body temperatures can be variously affected by environmental temperature (Helmuth \& Hofmann 2001; Seabra 2011; Lathlean et al. 2015; Seuront et al. 2019. All of these studies confirm that temperature is an important driving force that can influence the distribution of species on rocky seashores.

Comparing across studies that investigate substratum temperature, a number of rock temperature observations have been made. Rock temperature is affected by its colour (Raimondi 1988; Judge et al. 2011; Gunderson et al. 2019), size and orientation relative to the sun (Bertness 1999; Chapperon et al. 2016; Chapperon et al. 2017). Marshall et al. (2010) reported lighter-coloured sandstone was cooler than darker-coloured ferruginous sandstone. Furthermore, while Judge et al. (2011) failed to identify their rock lithology, they reported that black rock was hotter than white rock. These studies aside, it appears that the role of lithology (rock type) in affecting substrate temperature has been largely neglected to date. It is possible that the specific mineral constituents of different rock types influence their temperature 
characteristics, although this does not appear to have been investigated for rocky seashore substrata. Investigations of small granitic test cubes have shown that their different mineral constituents can have a temperature range of up to $4{ }^{\circ} \mathrm{C}$ (Gómez-Heras et al. 2006). Therefore, if ecologists are to accurately predict the future fate of species and populations under various climate change scenarios, how rock types and their specific mineralogies may affect temperature characteristics needs to be better understood.

Studies investigating intertidal rock temperature have also shown that observed substratum temperature is not homogenous (e.g. Huey et al. 1989; Gómez-Heras et al. 2006; Helmuth et al. 2006; Lathlean et al. 2012; Gunderson et al. 2019; Leal et al. 2020). Instead, substratum temperature is heterogeneous, with temperature differences up to $25.5^{\circ} \mathrm{C}$ identified between the hottest and coolest locations (e.g. Huey et al. 1989; Denny et al. 2011; Lathlean et al. 2012; Gunderson et al. 2019; Leal et al. 2020). The scale of these patterns of temperature difference can vary enormously, from many kilometres down to millimetres (Helmuth et al. 2006; Denny et al. 2011; Judge et al. 2011; Lathlean et al. 2012; Lathlean et al. 2013). Identifying the sources of this temperature heterogeneity can be difficult, with rocky seashores not being equal in terms of their physical attributes, with variations in latitude (Helmuth et al. 2006; Lathlean et al. 2014), shore slope (Helmuth \& Hofmann 2001; Harley 2008), azimuth (Helmuth \& Hofmann 2001; Harley 2008; Chapperon et al. 2017), microhabitat features (Chapperon \& Seuront 2011a; Judge et al. 2011; Lathlean et al. 2015), rock type (Raimondi 1988; Marshall et al. 2010; Judge et al. 2010); relative humidity (Lathlean et al. 2014), wave splash (Helmuth et al. 2006), the timing 
94 of low tide (Helmuth et al. 2002; 2006) and microtopography (Lathlean et al. 2012; Choi et al.

95 2019) all contributing to temperature heterogeneity.

96

97 To investigate how rock temperature characteristics may be affected by rock type, mineralogy, and boulder surface (upper versus lower), a common-garden experiment using boulders of six seashore rock types was established. Three rock temperature characteristics were investigated on the upper and lower surfaces of boulders, which were: the spatial arrangement (i.e. patterns) of temperature on boulder surfaces; the maximum surface temperature; and the surface temperature range (i.e. maxima - minima). We focused on maxima due to extreme temperatures having a greater impact on organism survival and fitness (e.g. Jones and Boulding 1999; Harley 2008; Gedan et al. 2011). Sampling was conducted over an 18-month timeframe to investigate whether daily weather conditions and seasonality affected rock temperature. We also quantified the mineralogy of each rock type and investigated which minerals were correlated with rocks showing different temperature characteristics. Consequently, this experimental approach allowed us to test the following four hypotheses:

1) boulders of different rock types have different patterns of temperature heterogeneity across

110 their surfaces;

2) the maximum temperature reflected from the rock surface differs between rock types and between the sun-exposed top and shaded bottom-surface of boulders;

113 3) the magnitude of the range in temperature differs between rock types or surfaces; and

114 4) rock-related differences in temperature maxima are correlated with their mineral 115 composition. 


\section{$117 \quad 2.0$ Materials \& methods}

\subsection{Boulder selection}

119 The geologically-diverse Fleurieu Peninsula of South Australia is comprised of a variety of rock

120 types. Six of these, in the form of small boulders ( $n=6$ boulders per rock type, maximum

121 dimension $\leq 30 \mathrm{~cm}$ ), were collected from four seashores (Appendix Figure A1). From Southport

$122\left(35^{\circ} 10^{\prime} \mathrm{S}, 138^{\circ} 27^{\prime} \mathrm{E}\right)$ boulders of either white fossiliferous limestone or orange fossiliferous

123 limestone were collected, while fossiliferous sandstone that was yellowish brown in colour was

124 collected from Seaford $\left(35^{\circ} 11^{\prime}\right.$ S, $138^{\circ} 28^{\prime}$ E) (Appendix Figures A1 \& A2). The two limestones

125 and the fossiliferous sandstone had coarse surface textures and complex surfaces that were

126 interspersed by cracks and depressions. From Marino Rocks ( $35^{\circ} 02^{\prime} \mathrm{S}, 138^{\circ} 30^{\prime} \mathrm{E}$ ) boulders of

127 both purple siltstone and grey siltstone were collected, while quartzite that was greyish to

128 yellow-brown in colour, was collected from O'Sullivan Beach (3507' S, $138^{\circ} 28^{\prime} \mathrm{E}$ ) (Appendix

129 Figures A1 \& A2). The two siltstones had smooth surface textures and featureless surfaces that

130 generally lacked cracks or depressions, while quartzite had coarse, angular surfaces that also

131 lacked cracks and depressions.

132

133 Six boulders of each rock type were collected (total $N=36$ ), with boulders specifically selected

134 to span the range of shapes and thicknesses that occurred for each type on each seashore

135 (Appendix Figure A2). Measurements of thickness were collected for each boulder to be used as

136 a co-variate in statistical analyses. However, as the boulders investigated had only a naturally 
137 narrow range of thicknesses $(6-14 \mathrm{~cm})$, boulder thickness was never a significant co-variate, and

138 was hence removed from all analyses to improve their statistical power.

139

140

\subsection{Experimental location}

141 Boulders were transplanted into a paddock on a farm at Kangarilla, which was located

142 approximately $20 \mathrm{~km}$ inland from the coast (Appendix Figure A1). This secure setting was

143 selected to be independent of any confounding variables. For example, had experimentation

144 been conducted at one of the seashores where boulders were sourced, variables such as wave

145 splash, tidal movement, sediment or wrack deposition, shading by cliffs, under-boulder

146 substratum or angle of repose may have affected the temperature of some boulders and not

147 others. Setting boulders into a sandy beach was not attempted due to the boulder losses

148 sustained during a translocation experiment in the same region (Liversage et al. 2014; Janetzki

149 et al. 2018). Issues with sand scour or burial of boulders by sand were also likely on a sandy

150 beach. Moreover, given the large population of the Adelaide region (1.3 million people in 2016),

151 interference with boulders left lying on a beach was considered likely.

152

153

\subsection{Design of the common-garden experiment}

154

155

156

157

158

A square plot measuring $3 \times 3$ metres was excavated to a depth of approximately 10 centimetres (Appendix Figure A2). The ironstone and soil matrix unearthed was replaced by washed yellow beach sand to simulate substrate matrices where experimental boulders were sourced (Appendix Figure A2). The location of this plot was selected to ensure it had an eastwest orientation (i.e. to follow the movement of the sun) free from any physical obstructions 
159 (e.g. buildings, trees) that might shade the plot. Boulders were arranged on the sand matrix in

160 four groups that each contained nine boulders (Appendix Figure A2). Boulders were arranged

161 such that each group could be sampled without accidently disturbing or shading other groups

162 (Appendix Figure A2). Boulders were randomly assigned to each group and their location was

163 re-randomised on four occasions. The boulder plot was covered with a tarpaulin to shelter

164 boulders from insolation prior to sampling, although small differences in surface temperature

165 among rock types were identified at time zero on several days sampled (Appendix Figures A3 \& 166 A4).

167

Rock temperatures were measured on 17 days spread over an 18-month period (Table 1). Each day was targeted for its forecast cloud cover and air temperature to investigate generally how rock temperature may be influenced by seasonality and daily weather conditions. Sampling was completed on days where no rainfall was forecast, as wet surfaces were likely to confound our ability to accurately measure rock temperature (Lathlean and Seuront 2014; Seuront et al. 2018). Approximately 20 minutes before the commencement of sampling, the tarpaulin was removed from the boulder plot and each boulder was submersed ( $<1$ minute) in a tub filled with seawater. Submersion wetted the boulder surfaces to simulate conditions on the seashore, where boulder surfaces are wet when first emersed by the receding tide. Each

177 boulder was returned to its specific spot in the plot where it was allowed to drain and dry (this

178 took no longer than 5-10 minutes as water rarely permeated boulder surfaces). There was no evidence of differential patterns of drying over this 5 - 10 minute timeframe among the six rock types investigated. 
182 The surface temperature of each boulder was measured at one-hour intervals, commencing at 1830900 hours and concluding at 1400 hours daily. This five-hour time course was selected to

184 simulate the average length of time boulders on local mid-lower seashores are emersed during 185 a single low tide (NJ unpublished data). The 0900 - 1400 start and finish times were selected to simulate the timing of summer daytime low tides for seashores on the Fleurieu Peninsula.

Sunrise occurred between 0555 hours during the height of summer and 0724 hours during the depths of winter.

Surface temperature was measured with a Fluke Ti20 thermal imaging camera (Fluke

Corporation, Everett). The thermal resolution of this camera was $\leq 0.2^{\circ} \mathrm{C}$ at $30^{\circ} \mathrm{C}$, with accuracy

to $2 \%$ or $2^{\circ} \mathrm{C}$, whichever was greater. Default camera settings were employed, including emissivity, which was set at 0.95 . This default emissivity was applied, even though emissivity may have differed within and among the rock types sampled, as previous thermography studies in the long-infrared range $(9-14 \mu \mathrm{m})$ have shown that the emissivity of dry rock generally ranges between 0.95 and 1 (Rivard et al. 1995; Danov et al. 2007; Cox and Smith 2011; Lathlean et al. 2012). Surface temperature was captured in situ, with archived thermal images processed later. Upper and lower boulder surfaces were imaged separately. In this study, lower surfaces are defined as the underside of the boulder that was in contact with the substratum and thus sheltered from insolation. Upper surfaces are defined as all remaining surfaces that were not in contact with the substratum and were potentially exposed to insolation. 
203 Thermal images were recorded for all upper surfaces first without touching boulders. For lower

204 surfaces, each boulder was briefly flipped upside down, and a thermal image recorded, before

205 the boulder was returned to its original position. Overall, a total 7344 thermal images were

206 collected. Air temperature and cloud cover were also recorded at one-hour intervals when

207 taking images. Air temperature was measured in the shade to the nearest degree Celsius with a

208 glass thermometer. Cloud cover (i.e. sky condition) was estimated by how many eighths of sky

209 were covered by cloud, which ranged from zero oktas (sunny, no clouds) to eight oktas (sky

210 completely cloudy, no sunshine) (Li and Lam 2001). Each day sampled was assigned to one of

211 two weather condition categories based on their cloud cover. Days where the cloud cover

212 never exceeded 3 oktas were assigned the 'sunny' category, while days where the cloud cover

213 exceeded 3 oktas during sampling were assigned the 'cloudy' category (Table 1).

215 Archived thermal images were subsequently processed using the InsidelR version 4.0 software

216 (Fluke Corporation, see Appendix for more information). The maximum and minimum

217 temperature of substrata were determined for each replicate surface, and a temperature range

218 (maximum - minimum) for each surface was calculated. The orientation, relative to the sun, for

219 the maximum temperature, was categorised as either occurring on the boulder side nearest the

220 sun, or on any other boulder side. Transects were drawn on images of boulder surfaces from

221 the centre of the boulder side nearest the sun to the centre of the side opposite to quantify

222 millimetre-to-centimetre scale patterns of temperature difference. Analysis of the temperature

223 patterns along transects was undertaken on three sunny and three cloudy days, spanning the 
224 range of maximum daily air temperatures sampled. Images for the zero-hour and four-hour

225 exposure times were investigated to look at changes across the day.

226

2272.4 XRF analyses

228 The mineralogy of each rock type was determined through X-Ray fluorescence (XRF) dispersion

229 analysis, with separate tests completed for major mineral and trace elemental composition for

230 three samples of each rock type. XRF analysis of each rock sample tested for 11 major minerals

231 and 40 trace elements, with concentrations returned as $\%$ and parts per thousand, respectively.

232 For major minerals, approximately one gram of each oven-dried sample (at $105^{\circ} \mathrm{C}$ ) was

233 accurately weighed with four grams of 12-22 lithium borate flux (Norrish and Hutton 1969). The

234 mixtures were heated to $1050{ }^{\circ} \mathrm{C}$ in a platinum/gold crucible for 20 minutes to completely

235 dissolve the sample, and then poured into a $32 \mathrm{~mm}$ platinum/gold mould heated to a similar

236 temperature (Norrish and Hutton 1969). The melt was cooled rapidly over a compressed air

237 stream and the resulting glass disks were analysed on a PANalyticalAxios Advanced wavelength

238 dispersive XRF system using the CSIRO in-house silicates calibration program. For trace

239 elements, approximately four grams of each oven-dried sample (at $105^{\circ} \mathrm{C}$ ) was accurately

240 weighed with one gram of Licowax binder and mixed well (Norrish and Hutton 1969). The

241 mixtures were pressed in a $32 \mathrm{~mm}$ die at 12 tons pressure and the resulting pellets were

242 analysed on a PANalyticalAxios Advanced wavelength dispersive XRF system using the CSIRO in-

243 house powders program (Norrish and Hutton 1969). 
246 Frequencies of occurrence (\%) for three patterns of temperature difference were tallied for the

247 upper and lower surfaces of boulders for all six rock types after four hours exposure to

248 insolation. Only data for three cloudy versus sunny days are presented, because each day is not

249 strictly independent of each other.

250

251 Line charts plotting temperature dependent variables (maxima, range) versus exposure time

252 were used to rank rock types in descending order from 6 (largest) to 1 (smallest) for their mean

253 temperature range and maxima, for each surface on each day after four hours. The sum of

254 ranks allocated to each rock type was then used to assign an overall rank to each rock type

255 from 6 (largest) to 1 (smallest) for their temperature range and maxima, with the highest

256 ranked rock types having the highest sum of ranks. Upper and lower surfaces were ranked

257 separately. To quantify changes over time exposed, dependent variables for the upper and

258 lower surface of each replicate boulder after four hours were subtracted from the same

259 dependent variables for the same replicate surface at zero hours. This gave values for the

260 change in maxima and temperature range over four hours, for the upper and lower surfaces of

261 each boulder, on each day sampled. Comparing the magnitude of change over four hours was

262 used in place of formal statistical tests, as measurements were made continuously for the same

263 boulders and thus were not independent. To establish whether dependent variables differed

264 between surfaces, upper-surface dependent variables were subtracted from lower-surface

265 dependent variables, for each replicate boulder, for each exposure time on each day sampled.

266 The resulting difference data were plotted as line charts to visually investigate surface

267 differences over the exposure period. 
Analyses were completed using PRIMER v7/PERMANOVA+ (PRIMER-e, Plymouth, UK), with significance set at $\alpha=0.05$. To test for mineralogical differences between rock types, separate multivariate analyses were completed for major mineral composition and trace element composition, with separate univariate analyses completed for the total content of each major mineral. Untransformed major-mineral data (measured as \% composition) were used, while fourth-root-transformed (necessary to down-weight several dominant elements) trace-element data (measured as parts per million) were used. Euclidean-distance resemblance matrices were prepared, and PERMutational Analyses Of VAriance (PERMANOVAs) were run to test for mineralogical differences between rock types. For multivariate data, constrained ordination Canonical Analysis of Principal coordinate (CAP) plots (Anderson et al. 2008) were used to visualise rock-related mineralogical differences. A leave-one-out procedure was used to test the allocation success of the discriminant function for rock groupings in CAP, with permutation tests used to test the significance of the trace test statistic and first canonical eigenvalue. Vector overlays of Spearman Rank correlations (for Rho values $>0.8$ ) were used to identify the major minerals and trace elements that best characterised the mineralogy of each rock type.

\subsection{Results}

3.1 Patterns of temperature difference on upper or lower surfaces of different rock types

Boulder upper and lower surfaces, for all six rock types, had generally a heterogeneous surface 
290

291

292

293

294

295

296

297

298

299

300

301

302

303

sampled (Figure 1). Moving in any direction across boulder surfaces (a representative thermal

image showing each rock type's surface temperature is provided in Figure 2), temperature consisted of warmer and cooler areas with patch sizes $<10 \mathrm{~cm}$. When transects were drawn on thermal images, three qualitative patterns of temperature difference were identified. The first pattern was a temperature mosaic, which consisted of heterogeneous temperatures across the entire boulder surface (Figure 3a). The temperature difference between the warmest and coolest mosaic areas was $\geq 5^{\circ} \mathrm{C}$. The second pattern was a temperature gradient, where temperature appeared to gradually decrease from the side nearest the sun to the side opposite (Figure 3b). The temperature difference between the warmest and coolest gradient areas was $\geq 5{ }^{\circ} \mathrm{C}$. The third pattern was limited temperature heterogeneity, which consisted of only small temperature differences $<5^{\circ} \mathrm{C}$ between the warmest and coolest areas (Figure 3c).

The frequency of occurrence for these three patterns of temperature difference was strongly influenced by daily weather conditions (Table 2 ). On cloudy days, almost all (>94 \%) boulder surfaces for all six rock types were categorised as having limited temperature heterogeneity (Table 2). Temperature mosaics and gradients were seldom, if ever, observed on cloudy days (Table 2 ). On the two cooler sunny days, almost all (>94 \%) boulder surfaces for all six rock types were categorised as having either temperature gradients or mosaics (Table 2). Temperature gradients were more common than temperature mosaics, in a ratio of 3:1, on these sunny days (Table 2). On the hottest sunny day, all three patterns of temperature difference were observed (Table 2); however, boulder surfaces became generally hot, with temperature differences between the warmest and coolest areas mostly $<5^{\circ} \mathrm{C}$ (Table 2, Figure 
312 1). As a result, limited temperature heterogeneity was the most common ( $\geq 78 \%)$ temperature

313 pattern identified on the hottest sunny day (Table 2), with gradients and mosaics observed at

314 much lower frequencies than on the other sunny days.

315

316 On sunny days patterns of temperature difference differed among rock types. The coarse, 317 angular surfaces of quartzite had a mosaic of fine millimetre to centimetre scale patches of

318 heterogeneous temperature (Figure 2c, Appendix Table A1). The five remaining rock types all

319 generally had temperature gradients, although the spatial arrangement of these gradients

320 differed. The generally smooth and featureless surfaces of siltstone had simple gradients of

321 warmer through cooler areas (Figure 2a-b, Appendix Table A1). In contrast, the two limestones

322 and fossiliferous sandstone had complex surfaces intersected by shallow depressions and pits

$323(<1 \mathrm{~cm}$ depth). Consequently, their temperature gradients were interrupted intermittently by

324 these depressions and pits, which could be either warmer or cooler (by up to $2-3{ }^{\circ} \mathrm{C}$ ) than the

325 flatter surfaces immediately around them (Figure $2 d-f$ ). All three patterns of temperature

326 difference were related to boulder orientation, with the hottest temperatures generally

327 recorded for the side of boulders nearest the sun (>92\%, Table 2). Each rock type generally had

328 the same pattern of temperature difference on its upper and lower surfaces. 
333 After four hours exposure the mean maximum temperature was hotter than the air

334 temperature for all six rock types on both surfaces, especially on sunny days (Figure 4a-b). The

335 maximum temperature of upper and lower surfaces generally increased with time, with

336 maxima often peaking around four hours and plateauing thereafter (Figure 5a). The largest

337 increases in maxima were generally recorded during the first two hours exposure to insolation,

338 with smaller increases (and sometimes decreases) recorded thereafter (Appendix Figures A3 \&

339 A4). After four hours, the hottest maximum recorded was $57.8^{\circ} \mathrm{C}$ (sunny day, air temperature $=$

$34039^{\circ} \mathrm{C}$ ) for the upper surface of grey siltstone while the coolest maximum was $14.4{ }^{\circ} \mathrm{C}$ (sunny

341 day, air temperature $=12^{\circ} \mathrm{C}$ ) for the lower surface of quartzite. Over four hours, increases in

342 mean maximum surface temperature $>20^{\circ} \mathrm{C}$ were recorded for some rock types on several

343 days, with the greatest increases recorded for upper surfaces on sunny days (Appendix Figure

344 A5).

345

346

When rock types were ranked from hottest to coolest mean maximum temperature after four

hours, a consistent rank order across replicate days was identified, irrespective of weather

conditions (Table 3). For both surfaces, the two siltstones consistently recorded the hottest

maxima, followed by fossiliferous sandstone and orange limestone in descending rank order

(Table 3, Figure 5a). On upper surfaces, white limestone consistently recorded the second

coolest maxima and quartzite the coolest, while on lower surfaces both rock types were equally

352 ranked in terms of the coolest maxima (Table 3). After four hours exposure for the 17 replicate 
355 over four hours for both surfaces (Table 3, Appendix Figure A5). The two siltstones generally

356 had the largest increase in maximum temperature, while white limestone and quartzite had the

357 smallest (Table 3, Appendix Figure A5).

358

359 Generally, maxima behaved similarly on upper and lower surfaces (Figure 4c). At the

360 commencement of sampling on most days, small negative differences were detected between

361 upper and lower surface maxima for all rock types, with lower surfaces having mean maxima

362 that were slightly hotter $\left(<2{ }^{\circ} \mathrm{C}\right)$ than upper surfaces (Appendix Figure A6). Thereafter, small

363 positive differences were detected between upper and lower surfaces for most rock types, with

364 upper surfaces having hotter mean maxima than lower surfaces, although these differences

never exceeded $5{ }^{\circ} \mathrm{C}$ (Figure 5b, Appendix Figure A6). The only notable exception to this trend

was quartzite, which generally had small negative differences throughout, with lower surfaces

sometimes having hotter mean maxima than upper surfaces (Figure 5b). The difference in

maxima between upper and lower surfaces was always smallest on cloudy days, with larger

over four hours exposure to insolation with the same trends identified for rock type, surface and time exposed (refer to minima sub-section in Appendix for more details).

\subsection{Temperature range does not consistently differ between rock types or surfaces}

374 Generally, temperature range behaved similarly on upper and lower surfaces (Appendix Figures 
377 was recorded on sunny days for both surfaces (Figure 5c, Appendix Figures A7 \& A8). In

378 contrast, a smaller temperature range (generally $<5^{\circ} \mathrm{C}$ ) that was less variable between rock

379 types and exposure times was recorded on each cloudy day for both surfaces (Appendix Figures

380 A7 \& A8). After four hours, the largest temperature range recorded was $16.3^{\circ} \mathrm{C}$ (sunny day, air

381 temperature $=15^{\circ} \mathrm{C}$ ) on the upper surface of grey siltstone while the smallest temperature

382 range was $1.6^{\circ} \mathrm{C}$ (cloudy day, air temperature $=38^{\circ} \mathrm{C}$ ) on the upper surface of purple siltstone.

When rock types were ranked from largest to smallest for the mean temperature range after

four hours, there was little evidence of a consistent ranking across replicate days for both upper

and lower surfaces (Table 4, Appendix Figures A7 \& A8). Rankings were similarly variable after

both shorter and longer exposure times, with rank order often changing from one exposure

time to the next (Appendix Figures A7 \& A8). No consistent ranking was identified either for the change in mean temperature range over four hours for either surface (Table 4, Appendix Figure A9).

The temperature range difference between upper and lower surfaces (i.e. upper range - lower

range) was always smallest on cloudy days, with larger differences detected on sunny days

(Appendix Figure A10). On cooler days with a maximum daily air temperature $<30^{\circ} \mathrm{C}$, regardless

of the day condition, small positive differences were generally detected, with the upper

surfaces of most boulders having a larger temperature range than lower surfaces (Appendix

Figure A10). In contrast, on hotter days with a maximum daily air temperature $\geq 30{ }^{\circ} \mathrm{C}$, small 
399

400

401

402

403

404

405

406

407

408

409

410

411

412

413

414

415

416

417

418

419

often measured for the two limestones and quartzite, with lower surfaces having a larger temperature range than upper surfaces (Appendix Figure A10). Overall, the two siltstones generally had the largest range difference between upper and lower surfaces, while white limestone and quartzite often had the smallest (Appendix Figure A10).

\subsection{Rock-related differences in maximum temperature are correlated with their mineral} composition

Silicon dioxide $\left(\mathrm{SiO}_{2}\right)$ and calcium oxide $(\mathrm{CaO})$ were the dominant major minerals detected, with orange limestone having a $\mathrm{CaO}$-dominated mineralogy and all other rock types a $\mathrm{SiO}_{2^{-}}$ dominated mineralogy (Appendix Table A3). Major mineral composition significantly differed among rock types (PERMANOVA permuted $p$-value $=0.0001)$. For rock type differences, a CAP constrained-ordination plot used five axes to discriminate major-mineral differences, with the first two axes accounting for $99.54 \%$ (prop. G) of the total mineralogical variability (Figure 6a).

All samples were correctly classified using a leave-one-out procedure, and permutation tests for both the trace test statistic $(p=0.0001)$ and first canonical eigenvalue $(p=0.0001)$ were highly significant. The vector overlay of Spearman rank correlations (for rho values $>0.8$ ) for major minerals associated with rock differences showed that each rock type had a specific majormineral composition (Figure 6a). Grey siltstone was characterised by higher aluminium oxide and potassium oxide contents, quartzite by the highest $\mathrm{SiO}_{2}$ content, and orange limestone and fossiliferous sandstone by higher $\mathrm{CaO}$ contents (Figure 6a). Rock type differences in the content of specific major minerals were also detected for 10 from 11 major minerals (largest significant 
420 permuted PERMANOVA $p$-value $=0.0330$ for magnesium oxide), with only sulfur trioxide not

421 differing between rock types (PERMANOVA permuted $p$-value $=0.1244$ ).

422

423 Trace-element composition significantly differed among rock types (PERMANOVA permuted $p$ -

424 value $=0.0001)$. For rock type differences, a CAP constrained-ordination plot used two axes to

425 discriminate trace-element differences, with these two axes accounting for $79.8 \%$ (prop. G) of

426 the total mineralogical variability (Figure $6 \mathrm{~b}$ ). Some $88.9 \%$ of samples were correctly classified

427 using a leave-one-out procedure, and permutation tests for both the trace test statistic $(p=$

$4280.0001)$ and first canonical eigenvalue $(p=0.0001)$ were highly significant. The vector overlay of

429 Spearman rank correlations (for rho values $>0.8$ ) for trace elements associated with rock type

430 differences suggested that each rock type had a specific trace-element composition (Figure 6b).

431 The two siltstones were characterised by a higher trace-metal content (manganese and

432 zirconium especially), quartzite by generally low trace-element quantities (although it had the

433 highest ytterbium content), and the two limestones and fossiliferous sandstone by a higher

434 chlorine content (Figure 6b, Appendix Table A4).

435

436 The vector overlay of Spearman rank correlations (for rho values $>0.8$ ) in CAP plots (Figure 6)

437 showed that the two siltstones, which consistently had the hottest maxima, had mineralogies

438 that were characterised by a higher content of metallic oxides and trace metals versus all other

439 rock types (Figure 6, Appendix Tables A3 \& A4). White limestone and quartzite, which

440 consistently had the coolest maxima, were characterised by the highest content of $\mathrm{SiO}_{2}$ and the

441 lowest content of most metallic oxides and trace metals versus all other rock types (Figure 6, 
442 Appendix Tables A3 \& A4). Meanwhile, orange limestone and fossiliferous sandstone, which

443 had intermediate maximum temperatures, were characterised by higher contents of $\mathrm{CaO}$ and

444 chlorine, and metallic oxide and trace metal quantities that were generally lower than the two

445 siltstones but greater than white limestone and quartzite (Figure 6, Appendix Tables A3 \& A4).

\section{4.0 Discussion}

447 Under common-garden conditions that simulated low tide, we were able to isolate temperature

448 that was a function of the rocks themselves, not their setting. Weather condition was the

449 largest determinant of boulder temperature, with cloud cover moderating all temperature

450 dependent variables. Air temperature was strongly associated with boulder temperature, with

451 the hottest boulder temperatures measured on the hottest sunny days. Upper and lower

452 surfaces had patterns of temperature difference, with three qualitative patterns identified:

453 gradients; mosaics; and limited heterogeneity. On cloudy days, limited heterogeneity was

454 identified on most surfaces for all rock types. On the hottest sunny day sampled, and with rocks

455 greatly heated, limited heterogeneity was again the dominant pattern identified, although

456 some temperature gradients and mosaics were observed. On the remaining sunny days, most

457 quartzite surfaces developed temperature mosaics, while the surfaces of all other rock types

458 generally developed temperature gradients. The maximum (and minimum) temperature

459 differed consistently between rock types and surfaces. Upper surface maxima were generally

460 hotter $\left(<5^{\circ} \mathrm{C}\right)$ than lower surface maxima, with the two siltstones consistently being the hottest

461 and quartzite and white limestone the coolest. Each rock type had a unique mineralogy. The

462 maximum temperature correlated with the metallic oxide and trace metal content of rocks,

463 with the hottest rock types having the highest metallic oxide and trace metal contents. 
465 These results provide evidence that rock type is likely to contribute to the heterogenous

466 patterns of temperature observed across rocky seashores. Under common-garden conditions,

467 differences in maximum surface temperature of up to $10.2{ }^{\circ} \mathrm{C}$ were identified among the six rock types. This experimental observation supports field data previously collected on rocky seashores, which show different rock types can have different surface temperatures (Raimondi 1988; Marshall et al. 2010; Judge et al. 2011). Besides differences in temperature, the six rock types investigated also support different patterns of temperature variation across the boulder surface. For example, temperature mosaics were generally observed on quartzite boulders

473 only. These temperature mosaics may have developed because of the specific

474 microtopographic features of quartzite (i.e. coarse, angular surfaces), with microtopography associated with temperature heterogeneity on rocky seashores elsewhere (Lathlean et al. 2012;

476 Choi et al. 2019). Alternatively, these mosaics may reflect differences in long-wave emissivity not accounted for by our use of a generic emissivity value. Future studies should investigate emissivity variation across quartzite surfaces to provide a better understanding of how

479 microtopography and emissivity interact to create temperature mosaics. Microhabitat features 480 like cracks and depressions were unique to limestone and sandstone boulders here. These microhabitat features were always a different temperature to the flat surfaces immediately

482 around them, with microhabitat features associated with temperature heterogeneity on other 483 rocky substrates (Chapperon \& Seuront 2011a; Judge et al. 2011; Lathlean et al. 2015).

484 Extrapolating these results to the larger spatial scale of natural rocky seashores, our 
485

486

487

488

489

490

491

492

493

494

495

496

497

498

499

500

501

502

503

504

505

506

experimental results indicate that rock type contributes to the temperature heterogeneity observed within and among rocky seashores.

Patterns of temperature difference were related to boulder orientation, with the hottest locations on all rocks generally observed on the side of boulders nearest the sun. Substrate orientation appears to affect the spatial arrangement of temperatures on rocky seashores generally, with rock faces orientated towards the sun (Harley 2008; Seabra et al. 2011;

Chapperon et al. 2016; Chapperon et al. 2017; Aguilera et al. 2019) having the hottest surface temperatures. The potential biological relevance of the temperature patterns on boulder surfaces identified in this study have not yet been quantified. However, given that periwinkles will select cooler locations when offered centimetre-scale temperature gradients (Soto and Bozinovic 1998), and intertidal ectotherms generally can respond to habitat-scale temperature mosaics (e.g. Garrity 1984; Chapperon and Seuront 2011a; Judge et al. 2011; Chapperon et al. 2013), it is possible that mobile intertidal ectotherms may respond to the temperature patterns on boulder surfaces described here.

On the hottest sunny day sampled, boulder surfaces became generally uniformly hot with limited temperature heterogeneity. These uniformly hot boulder surfaces may represent the upper threshold of extreme thermal habitats for intertidal biota on boulders with a maximum dimension $<30 \mathrm{~cm}$, as the boulders sampled here were relatively thin. Given the risks that desiccation and heat stress pose to organism survival and fitness (e.g. Jones and Boulding 1999; Harley 2008; Gedan et al. 2011; Monaco et al. 2015), and the exacerbation of these risks at the 
507 hottest environmental temperatures (Harley 2008; Seuront et al. (2019)), the disappearance of

508 temperature mosaics and gradients on hot, sunny days may be problematic for intertidal biota.

509 If the cooler areas of mosaics or gradients are found to function as thermal refuges for

510 intertidal biota, but these refuges disappear on the hottest days when they are needed most,

511 then the thermal quality of these boulder habitats may be diminished on hot, sunny days.

512 Consequently, organism survival and fitness may be challenged.

513

514 Maximum temperatures differed consistently among rock types, with the two siltstones always

515 hottest and white limestone and quartzite the coolest. Rock types with the coolest

516 temperatures were also the most thermally stable, as they had the smallest temperature

517 increases while exposed to insolation over four hours. Thus, some rock types possibly minimise

518 thermal stress to biota more than others. The mechanisms that resulted in some rock types

519 warming more slowly than others were not investigated here, but may be related to rock type

520 differences in the amount infrared energy absorbed/reflected or the thermal conductance of

521 specific mineral constituents (Seuront et al. 2018). Variations in thickness also affect the

522 thermal stability of boulders (Huey et al. 1989), but as the boulders sampled here were

523 standardised for size and were relatively thin, variations in thickness are unlikely to account for

524 the different warming rates of these six rock types.

525

526 The thermal benefits of cooler rock types may be observed across the entire vertical gradient of

527 the rocky intertidal zone. Lower on the shore, where some biota have only low thermal

528 tolerances (McMahon 1990; Madeira et al. 2012), cooler rock types that only warm small 
529 amounts when emersed may offer thermal refuges to thermally-sensitive species. Higher up

530 the shore, where biota generally have greater thermal tolerances (McMahon 1990; Madeira et

531 al. 2012), cooler rock types may not warm to potentially deleterious temperatures during

532 extended periods of emersion. These characteristics have not been recognised to date but

533 could allow some predictions of the future fate of populations and assemblages on rocky

534 seashores.

535

536 Cooler rock temperatures have been positively associated with intertidal biota on seashores

537 globally. In Mexico, the higher vertical distribution of barnacles on granite than basalt shores

538 was attributed to granite's cooler surface temperatures (Raimondi 1988), while in Brunei

539 Darussalam snail mimics had cooler body temperatures on lighter-coloured sandstone than

540 darker-coloured ferruginous sandstone (Marshall et al. 2010). In Australia, barnacle recruitment

541 and growth rate was higher on cooler than hotter areas of grey siltstone platform (Lathlean et

542 al. 2013), while in Brazil and Panama, post-settlement mortality of barnacles was higher on

543 hotter black plates than cooler white plates (Leal et al. 2020). Moreover, invertebrate and algal

544 abundance and richness was negatively related with peaks in substrate temperature in Chile

545 (Aguilera et al. 2019), while on igneous seashores in Panama, gastropod body temperatures and

546 mortality were highest in areas with the hottest temperature (Garrity 1984). Therefore, the

547 cooler and more thermally-stable rock types identified here such as white limestone and

548 quartzite may function as thermal refuges for some intertidal biota. If boulders comprised of

549 cooler rock types are available to biota seeking refuge, then the thermal benefits that cooler 
550 rocks potentially confer may improve the chances of biota surviving while emersed, and thus

551 persisting, compared to hotter rock types such as siltstone.

552

553 In this study, the metallic oxide and trace metal content of rocks correlated positively with

554 higher maximum temperatures. On the basis of these results, metallic minerals may increase

555 the thermal conductance of some rock types and increase the amount of infrared radiation they

556 absorb (Seuront et al. 2018). However, mineralogy is just one potential driver of the

557 temperature differences identified here. Differences in colour (Raimondi 1988; Marshall et al.

558 2010; Judge et al. 2011) and microtopography (Lathlean et al. 2012; Choi et al. 2019) have been

559 shown previously to affect rock temperature, with the six rock types investigated here also

560 differing in these attributes. It is possible that the smooth, featureless surfaces of siltstone were

561 able to reach hotter surface temperatures versus the coarse, textured surfaces of limestone

562 and quartzite. Moreover, darker rocks of the same type (i.e. purple versus grey siltstone and

563 orange versus white limestone, Appendix Figure A2) attained hotter surface temperatures.

564 However, as colour and microtopography differences between rock types were not

565 quantitatively measured it is difficult to reliably associate either variable with any rock-related

566 temperature differences.

567

568 Lower surfaces generally had cooler maximum temperatures $\left(<5^{\circ} \mathrm{C}\right)$ than upper surfaces. Over

569 four hours exposure to insolation, a greater increase in maxima was measured on boulder

570 upper than lower surfaces. Therefore, lower surfaces have some temperature benefits over

571 upper surfaces due to their shaded surfaces generally providing cooler maxima and slower 
572 temperature increases. The thermal benefits of living underneath boulders are often cited

573 (Evans 1948; Chapperon and Seuront 2011a; Chapperon et al. 2013). However, our results, in

574 conjunction with those published previously for the same siltstone boulders (Chapperon and

575 Seuront 2011a; Chapperon et al. 2013), suggest that the magnitude of temperature relief that

576 biota experience under boulders on the mid-lower seashore at this site may be quite small $(<5$

$577{ }^{\circ} \mathrm{C}$ ) when compared to temperature differences of up to $25.5^{\circ} \mathrm{C}$ between sun-exposed and sun-

578 protected microhabitats elsewhere on rocky seashores (e.g. Denny et al. 2011; Lathlean et al.

579 2012). These small temperature differences between upper and lower surfaces may be

580 attributed to the relatively thin boulders that naturally occur on the Fleurieu Peninsula, with

581 thicker or larger boulders on seashores elsewhere potentially having larger temperature

582 differences between upper and lower surfaces. Nevertheless, from a physiological perspective,

583 this $5^{\circ} \mathrm{C}$ difference between the top and bottom of boulders may help to ensure organisms

584 remain within their thermal tolerance limits (Helmuth et al. 2002). Moreover, the combined

585 benefits of cooler surface temperatures plus under-boulder dampness and shading from

586 insolation (Evans 1948; Chapman 2003; Chapperon et al. 2013) may interact to make lower

587 surfaces a thermally favourable habitat for intertidal biota at low tide.

588

589 Temperature range was highly variable among the six rock types, with no single rock type

590 having a temperature range that was consistently distinct from the others. If these sorts of

591 results extend to the seashore, then biota would have ample opportunity to respond to the

592 range of temperatures on all rock types, as no single rock type had a temperature range larger

593 or smaller than the others. In this study, a temperature range as large as $16.3^{\circ} \mathrm{C}$ was recorded 
594 across an individual boulder surface. This temperature range is larger than the $5.0^{\circ} \mathrm{C}$ (Leal et al.

5952020 ) or $8.2^{\circ} \mathrm{C}$ (Lathlean et al. 2012) maximum ranges recorded among replicate quadrats

596 sampled on the same rock platforms, but considerably smaller than the $24.0^{\circ} \mathrm{C}$ maximum range

597 detected between the edge and centre of rocks (maximum length $<2 \mathrm{~m}$ ) sheltering garter

598 snakes (Huey et al. 1989), the $25^{\circ} \mathrm{C}$ maximum range detected replicate boulders sampled on

599 the same seashore (Gunderson et al. 2019), or the $25.5^{\circ} \mathrm{C}$ maximum range detected between

600 different seashore microhabitats (Chapperon and Seuront 2011a; Chapperon et al. 2017).

601 Consequently, these new results for single boulder surfaces indicate that temperature range is

602 likely be specific to the type(s) of substrate, habitat and region investigated.

603

\section{$604 \quad 5.0$ Conclusions}

605 Under common-garden conditions, the upper and lower surfaces of boulders had patterns of 606 temperature difference, with three qualitative patterns identified: gradients; mosaics; and

607 limited heterogeneity. Maximum temperature differed consistently between rock types and

608 surfaces, with upper boulder surfaces generally $<5{ }^{\circ} \mathrm{C}$ warmer than lower boulder surfaces.

609 Each rock type had a unique major mineral and trace elemental composition, with the content

610 of metallic oxides and trace metals in rock types correlating with their maximum temperature.

611 The lower surface of rock types with the lowest metallic oxide and trace metal content

612 (quartzite and white limestone in this study) potentially offer the best thermal refugia for

613 intertidal biota on the mid-lower seashore during summer. Consequently, these results show

614 that rock type, mineralogy, and boulder surface, which have largely been neglected from 
615 investigations of substrate temperature until now, can play important roles in contributing to

616 the temperature heterogeneity observed on rocky seashores globally.

617

618 Acknowledgements

619 This work is dedicated to the memory of our mentor and co-author Peter G. Fairweather, who 620 sadly passed away prior to the publication of this work. He was an incredible marine ecologist, 621 and an even better friend. He had a profound and lasting impact on every scientist he inspired, 622 ourselves included. We are grateful to S. Hawkins, P. Raimondi, B. Helmuth and two anonymous 623 referees for useful comments and suggestions on earlier versions of this work. We are 624 especially grateful to $\mathrm{Dr}$ G. Napier for providing access to her farm, thus enabling us to 625 construct the boulder plot where this common-garden experiment was run. We are also 626 grateful to C. Flaxman for identifying rock samples and to M. Raven (CSIRO Land and Water, 627 Adelaide) for completing and commenting upon XRF analyses of rock samples.

Reference list

Anderson MJ, Gorley R, Clarke KR (2008) PERMANOVA+ for PRIMER: Guide to software and statistical methods. PRIMER-E, Plymouth

Aguilera M, Arias R \& Manzur T (2019) Mapping microhabitat thermal patterns in artificial breakwaters: Alteration of intertidal biodiversity by higher rock temperature. Ecology and Evolution 9: 12915-12927 
636 Bertness MD (1989) Intraspecific competition and facilitation in a northern acorn barnacle 637 population. Ecology 70: 257-268

638 Bertness MD (1999) The Ecology of Atlantic Shorelines. Sinauer Associates Inc, Sunderland, USA 639 Caddy-Retalic S, Benkendorff K, Fairweather PG (2011) Visualizing hotspots: applying thermal 640 imaging to monitor internal temperatures in intertidal gastropods. Molluscan Research 31: $641 \quad 106-113$

642 Chapman MG (2003) Paucity of mobile species on constructed seawalls: effects of urbanization 643 on biodiversity. Marine Ecology Progress Series 264: 21-29

644 Chapperon C, Le Bris C, Seuront L (2013) Thermally mediated body temperature, water content 645 and aggregation behaviour in the intertidal gastropod Nerita atramentosa. Ecological $646 \quad$ Research 28: 407-416

647 Chapperon C, Seuront L (2011a) Space-time variability in environmental thermal properties and 648 snail thermoregulatory behaviour. Functional Ecology 25: 1040-1050

Chapperon C, Seuront L (2011b) Behavioral thermoregulation in a tropical gastropod: links to 650 climate change scenarios. Global Change Biology 17: 1740-1749

651 Chapperon C, Studerus K, Clavier J (2017) Mitigating thermal effect of behaviour and 652 microhabitat on the intertidal snail Littorina saxatilis (Olivi) over summer. Journal of 653 Thermal Biology 67: 40-48

654 Chapperon C, Volkenborn N, Clavier J, Séité S, Seabra R, Lima FP (2016) Exposure to solar 655 radiation drives organismal vulnerability to climate: Evidence from an intertidal limpet. 656 Journal of Thermal Biology 57: 92-100 
657 Choi F, Gouhier T, Lima F, Rilov G, Seabra R, Helmuth B (2019). Mapping physiology: biophysical 658 mechanisms define scales of climate change impacts. Conservation Physiology 7: coz028 659 Connell JH (1972) Community interactions on marine rocky intertidal shores. Annual Review of $660 \quad$ Ecology and Systematics 3: 169-192

661 Cox TE, Smith CM (2011) Thermal ecology on an exposed algal reef: infrared imagery a rapid 662 tool to survey temperature at local spatial scales. Coral Reefs 30: 1109-1120

663 Danov, M, Vitchko T, Stoyanov D (2007) Measuring the spectral emissivity of rocks and the 664 minerals that form them. SPIE Newsroom doi:1200707

665 Denny MW, Dowd WW, Bilir L, Mach KJ (2011) Spreading the risk: small-scale body temperature 666 variation among intertidal organisms and its implications for species persistence. Journal of 667 Experimental Marine Biology and Ecology 400: 175-190

668 Evans RG (1948) The lethal temperatures of some common British littoral molluscs. The Journal 669 of Animal Ecology 17: 165-173

670 Garrity SD (1984) Some adaptations of gastropods to physical stress on a tropical rocky shore.

$671 \quad$ Ecology 65: 559-574

672 Gedan KB, Bernhardt J, Bertness MD, Leslie HM (2011) Substrate size mediates thermal stress in 673 the rocky intertidal. Ecology 92: 576-582

674 Gómez-Heras M, Smith BJ, Fort R (2006) Surface temperature differences between minerals in 675 crystalline rocks: Implications for granular disaggregation of granites through thermal 676 fatigue. Geomorphology 78: 236-249

677 Gunderson AR, Abegaz M, Ceja AY, Lam EK, Souther BF, Boyer K, King EE, You Mak KT, 678 Tsukimura B, Stillman JH (2019) Hot rocks and not-so-hot rocks on the seashore: patterns 
679

680

681

682

683

684

685

686

687

688

689

690

691

692

693

694

695

696

697

698

699

700

and body-size dependent consequences of microclimatic variation in intertidal zone boulder habitat. Integrative Organismal Biology 1: 1-15

Harley CDG (2003) Abiotic stress and herbivory interact to set range limits across a twodimensional stress gradient. Ecology 84: 1477-1488

Harley CDG (2008) Tidal dynamics, topographic orientation, and temperature-mediated mass mortalities on rocky shores. Marine Ecology Progress Series 371: 37-46

Helmuth, B (1999) Thermal biology of rocky intertidal mussels: quantifying body temperatures using climatological data. Ecology 80: 15-34

Helmuth B, Broitman BR, Blanchette CA, Gilman S, Halpin P, Harley CD, O'Donnell MJ, Hofmann GE, Menge B, Strickland D (2006) Mosaic patterns of thermal stress in the rocky intertidal zone: implications for climate change. Ecological Monographs 76: 461-479

Helmuth B, Harley CD, Halpin PM, O'Donnell M, Hofmann GE, Blanchette CA (2002) Climate change and latitudinal patterns of intertidal thermal stress. Science 298: 1015-1017

Helmuth BST, Hofmann GE (2001) Microhabitats, thermal heterogeneity, and patterns of physiological stress in the rocky intertidal zone. The Biological Bulletin 201: 374-384

Huey RB, Peterson CR, Arnold SJ, Porter WP (1989) Hot rocks and not-so-hot rocks: retreat-site selection by garter snakes and its thermal consequences. Ecology 70: 931-944

IPCC (2013) Climate Change 2013: The Physical Science Basis. Contribution of Working Group 1 to the Fifth Assessment Report of the Intergovernmental Panel on Climate Change. In: Stocker T, Qin D, Plattner G, Tignor M, Allen S, Boschung J, Nauels A, Xia Y, Bex V, Midgley P (eds) Climate Change 2013. Cambridge University Press, Cambridge, United Kingdom and New York, NY, USA, pp 1-1535 
701 Janetzki N, Fairweather PG, Benkendorff K (2018) Assemblages on limestone and siltstone

702 boulders diverge over six years in a primary-succession transplant experiment. Marine

$703 \quad$ Ecology Progress Series 604: 21-32

704 Jones KMM, Boulding EG (1999) State-dependent habitat selection by an intertidal snail: the

705 costs of selecting a physically stressful microhabitat. Journal of Experimental Marine

$706 \quad$ Biology and Ecology 242: 149-177

707 Judge ML, Botton ML, Hamilton MG (2011) Physiological consequences of the supralittoral

708 fringe: microhabitat temperature profiles and stress protein levels in the tropical

709 periwinkle Cenchritis muricatus (Linneaus, 1758). Hydrobiologia 675: 143

710 Lamb EA, Leslie HM, Shinen JL (2014) Both like it hot? Influence of temperature on two co-

711 occurring intertidal barnacles in central Chile. Journal of Experimental Marine Biology and

$712 \quad$ Ecology 453: 54-61

713 Lathlean JA, Ayre DJ, Coleman RA, Minchinton TE (2015) Using biomimetic loggers to measure

714 interspecific and microhabitat variation in body temperatures of rocky intertidal

715 invertebrates. Marine and Freshwater Research 66: 86-94

716 Lathlean JA, Ayre DJ, Minchinton TE (2012) Using infrared imagery to test for quadrat-level

717 temperature variation and effects on the early life history of a rocky-shore barnacle.

$718 \quad$ Limnology and Oceanography 57: 1279-1291

719 Lathlean JA, Ayre DJ, Minchinton TE (2013) Temperature variability at the larval scale affects

720 early survival and growth of an intertidal barnacle. Marine Ecology Progress Series 475:

$721 \quad 155-166$ 
722 Lathlean JA, Ayre DJ, Minchinton TE (2014) Estimating latitudinal variability in extreme heat 723 stress on rocky intertidal shores. Journal of Biogeography 14: 1478-1491

724 Lathlean J, Seuront L (2014) Infrared thermography in marine ecology: methods, previous 725 applications and future challenges. Marine Ecology Progress Series 514: 263-277

Leal I, Flores A, Archambault P, Collin R, Tremblay R (2020) Response of tropical and subtropical

727 chthamalid barnacles to increasing substrate temperatures. Journal of Experimental

$728 \quad$ Marine Biology and Ecology 524: 151281

729

730

731

732

733

734

735

736

737

738

739

740

741

742

Li DH, Lam JC (2001) An analysis of climatic parameters and sky condition classification. Building and Environment 36: 435-445

Liversage K, Janetzki N, Benkendorff K (2014) Associations of benthic fauna with different rock types, and evidence of changing effects during succession. Marine Ecology Progress Series 505: 131-143

Madeira D, Narciso L, Cabral HN, Vinagre C (2012) Thermal tolerance and potential impacts of climate change on coastal and estuarine organisms. Journal of Sea Research 70: 32-41

McMahon RF (1990) Thermal tolerance, evaporative water loss, air-water oxygen consumption and zonation of intertidal prosobranchs: a new synthesis. Hydrobiologia 193: 241-260

Marshall DJ, McQuaid CD, Williams GA (2010) Non-climatic thermal adaptation: implications for species' responses to climate warming. Biology Letters 6: 669-673

Monaco CJ, Wethey DS, Gulledge S, Helmuth B (2015) Shore-level size gradients and thermal refuge use in the predatory sea star Pisaster ochraceus: the role of environmental stressors. Marine Ecology Progress Series 539: 191-205 
743 Norrish K, Hutton JT (1969) An accurate X-ray spectrographic method for the analysis of a wide 744 range of geological samples. Geochimica et Cosmochimica Acta 33: 431-453

745 Pörtner HO, Farrell AP (2008) Physiology and climate change. Science: 690-692

746 Raimondi PT (1988) Rock type affects settlement, recruitment, and zonation of the barnacle

747 Chthamalus anisopoma Pilsbury. Journal of Experimental Marine Biology and Ecology 123:

$748 \quad 253-267$

749 Rivard B, Thomas PJ, Giroux J (1995) Precise emissivity of rock samples. Remote Sensing of

$750 \quad$ Environment 54: 152-160

751 Evans R, Wethey DS, Santos AM, Lima FP (2011) Side matters: microhabitat influence on

752 intertidal heat stress over a large geographical scale. Journal of Experimental Marine

753 Biology and Ecology 400: 200-208

754 Seuront L, Ng TP, Lathlean JA (2018) A review of the thermal biology and ecology of molluscs,

755 and of the use of infrared thermography in molluscan research. Journal of Molluscan

$756 \quad$ Studies 84: 203-232

757 Seuront L, Nicastro K, Zardi G, Goberville E (2019) Decreased thermal tolerance under recurrent

758 heat stress conditions explains summer mass mortality of the blue mussel Mytilus edulis

759 (2019) Scientific Reports 9: 1-14.

760

Somero GN (2002) Thermal physiology and vertical zonation of intertidal animals: optima, limits, and costs of living. Integrative and Comparative Biology 42: 780-789

Soto R, Bozinovic F (1998) Behavioral thermoregulation of the periwinkle Nodilittorina peruviana inhabiting the rocky intertidal of central Chile: a laboratory and field study. 


\section{Table $\mathbf{1}$ (on next page)}

The maximum cloudiness and air temperature recorded during sampling on each day, and the weather condition category that each day was subsequently allocated to based on its maximum cloudiness.

Days are arranged in each weather condition category according to increasing maximum air temperatures. 


\begin{tabular}{llcc}
\hline $\begin{array}{l}\text { Weather } \\
\text { condition }\end{array}$ & Date & $\begin{array}{c}\text { Maximum } \\
\text { cloudiness (Okta) }\end{array}$ & $\begin{array}{c}\text { Maximum air } \\
\text { temperature }\left({ }^{\circ} \mathbf{C} \text { ) }\right.\end{array}$ \\
\hline Cloudy & & & \\
& $09 / 09 / 2015$ & 8 & 15 \\
& $18 / 09 / 2015$ & 7 & 17 \\
& $06 / 10 / 2015$ & 7 & 21 \\
& $25 / 11 / 2015$ & 8 & 30 \\
& $19 / 12 / 2015$ & 8 & 38 \\
Sunny & & & \\
& $16 / 07 / 2016$ & 0 & 12 \\
& $10 / 09 / 2015$ & 0 & 15 \\
& $17 / 10 / 2015$ & 0 & 22 \\
$17 / 04 / 2017$ & 3 & 23 \\
& $02 / 10 / 2015$ & 0 & 24 \\
$07 / 01 / 2016$ & 0 & 29 \\
& $07 / 02 / 2016$ & 0 & 31 \\
& $06 / 02 / 2016$ & 0 & 33 \\
& $09 / 10 / 2015$ & 3 & 34 \\
$19 / 11 / 2015$ & 0 & 39 \\
$08 / 02 / 2017$ & 0 & 40 \\
& $18 / 11 / 2015$ & 0 &
\end{tabular}




\section{Table 2 (on next page)}

Frequencies of occurrence (\%), pooled across rock types, for the three patterns of temperature difference and the orientation of the maximum in relation to the sun.

For boulder upper and lower surfaces $(n=36)$ for a subset of the cloudy and sunny days sampled. 


\begin{tabular}{|c|c|c|c|c|c|c|c|c|}
\hline \multirow[b]{2}{*}{ Weather } & \multirow[b]{2}{*}{ Date } & \multirow{2}{*}{$\begin{array}{l}\text { Maximum air } \\
\text { temperature }\left({ }^{\circ} \mathrm{C}\right)\end{array}$} & \multirow[b]{2}{*}{ Surface } & \multicolumn{3}{|c|}{ Temperature pattern (\%) } & \multicolumn{2}{|c|}{ Orientation (\%) } \\
\hline & & & & Mosaic & Gradient & Limited heterogeneity & Side facing sun & Any other side \\
\hline \multirow[t]{6}{*}{ Cloudy } & 09/09/2015 & 15 & Upper & 0 & 0 & 100 & 91.6 & 8.4 \\
\hline & & & Lower & 0 & 0 & 100 & 100 & 0 \\
\hline & $25 / 11 / 2015$ & 30 & Upper & 0 & 0 & 100 & 100 & 0 \\
\hline & & & Lower & 0 & 0 & 100 & 100 & 0 \\
\hline & $19 / 12 / 2015$ & 38 & Upper & 0 & 0 & 100 & 97.2 & 2.8 \\
\hline & & & Lower & 0 & 5.6 & 94.4 & 94.4 & 5.6 \\
\hline \multirow[t]{6}{*}{ Sunny } & $16 / 07 / 2016$ & 12 & Upper & 13.9 & 86.1 & 0 & 100 & 0 \\
\hline & & & Lower & 13.9 & 80.5 & 5.6 & 100 & 0 \\
\hline & $07 / 02 / 2016$ & 29 & Upper & 22.2 & 75.0 & 2.8 & 100 & 0 \\
\hline & & & Lower & 25.0 & 75.0 & 0 & 94.4 & 5.6 \\
\hline & $18 / 11 / 2015$ & 40 & Upper & 2.8 & 19.4 & 77.8 & 100 & 0 \\
\hline & & & Lower & 5.6 & 33.3 & 61.1 & 94.4 & 5.6 \\
\hline
\end{tabular}




\section{Table 3 (on next page)}

The daily rank order of rock types from largest to smallest ( $6=$ largest, $1=$ smallest) maximum temperature after four hours and change in maximum temperature over four hours for upper and lower surfaces.

Entries are the cumulative number of occurrences of that daily rank for each rock type. The rank sum (sum of daily ranks) was used to assign an overall rank to each rock type from largest to smallest $(6=$ largest value, $1=$ smallest $)$. 


\begin{tabular}{|c|c|c|c|c|c|c|c|c|c|c|c|c|c|c|c|c|c|}
\hline \multirow[b]{2}{*}{ Measure } & \multirow{2}{*}{ Surface } & \multicolumn{8}{|c|}{ Upper } & \multicolumn{8}{|c|}{ Lower } \\
\hline & & 6 & 5 & 4 & 3 & 2 & 1 & $\begin{array}{l}\text { Rank } \\
\text { sum }\end{array}$ & $\begin{array}{c}\text { Overall } \\
\text { Rock } \\
\text { rank }\end{array}$ & 6 & 5 & 4 & 3 & 2 & 1 & $\begin{array}{l}\text { Rank } \\
\text { sum }\end{array}$ & $\begin{array}{c}\text { Overall } \\
\text { Rock } \\
\text { rank }\end{array}$ \\
\hline \multirow{6}{*}{$\begin{array}{l}\text { Maximum } \\
\text { temperature } \\
\text { after four } \\
\text { hours }\end{array}$} & Purple siltstone & 14 & 3 & 0 & 0 & 0 & 0 & 99 & 6 & 7 & 10 & 0 & 0 & 0 & 0 & 92 & 5 \\
\hline & Grey siltstone & 3 & 14 & 0 & 0 & 0 & 0 & 88 & 5 & 10 & 7 & 0 & 0 & 0 & 0 & 95 & 6 \\
\hline & Fossiliferous sandstone & 0 & 0 & 16 & 1 & 0 & 0 & 67 & 4 & 0 & 0 & 16 & 1 & 0 & 0 & 67 & 4 \\
\hline & Orange limestone & 0 & 0 & 1 & 16 & 0 & 0 & 52 & 3 & 0 & 0 & 1 & 15 & 1 & 0 & 51 & 3 \\
\hline & White limestone & 0 & 0 & 0 & 0 & 13 & 4 & 30 & 2 & 0 & 0 & 0 & 0 & 9 & 8 & 26 & 1 \\
\hline & Quartzite & 0 & 0 & 0 & 0 & 4 & 13 & 21 & 1 & 0 & 0 & 0 & 1 & 7 & 9 & 26 & 1 \\
\hline \multirow{6}{*}{$\begin{array}{l}\text { Change in } \\
\text { maximum } \\
\text { temperature } \\
\text { over four hours }\end{array}$} & Purple siltstone & 8 & 7 & 1 & 0 & 1 & 0 & 89 & 6 & 9 & 3 & 4 & 0 & 0 & 1 & 86 & 5 \\
\hline & Grey siltstone & 7 & 8 & 0 & 1 & 1 & 0 & 87 & 5 & 5 & 10 & 0 & 2 & 0 & 0 & 86 & 5 \\
\hline & Fossiliferous sandstone & 2 & 0 & 14 & 1 & 0 & 0 & 71 & 4 & 1 & 4 & 6 & 6 & 0 & 0 & 68 & 4 \\
\hline & Orange limestone & 0 & 1 & 2 & 13 & 1 & 0 & 54 & 3 & 1 & 0 & 6 & 6 & 4 & 0 & 56 & 3 \\
\hline & White limestone & 0 & 1 & 0 & 1 & 9 & 6 & 32 & 2 & 1 & 0 & 0 & 2 & 3 & 11 & 29 & 2 \\
\hline & Quartzite & 0 & 0 & 0 & 1 & 5 & 11 & 24 & 1 & 0 & 0 & 1 & 1 & 10 & 5 & 32 & 1 \\
\hline
\end{tabular}




\section{Table 4 (on next page)}

The daily rank order of rock types from largest to smallest $(6=$ largest value, $1=$ smallest) temperature range after four hours and change in temperature range over four hours for upper and lower surfaces.

Entries are the cumulative number of occurrences of that daily rank for each rock type. The rank sum (sum of daily ranks) was used to assign an overall rank to each rock type from largest to smallest $(6=$ largest value, $1=$ smallest $)$. 


\begin{tabular}{|c|c|c|c|c|c|c|c|c|c|c|c|c|c|c|c|c|c|}
\hline \multirow[b]{2}{*}{ Measure } & \multirow[b]{2}{*}{ Rock type } & \multicolumn{8}{|c|}{ Upper } & \multicolumn{8}{|c|}{ Lower } \\
\hline & & 6 & 5 & 4 & 3 & 2 & 1 & $\begin{array}{l}\text { Rank } \\
\text { sum }\end{array}$ & $\begin{array}{l}\text { Overall } \\
\text { rock rank }\end{array}$ & 6 & 5 & 4 & 3 & 2 & 1 & $\begin{array}{l}\text { Rank } \\
\text { sum }\end{array}$ & $\begin{array}{l}\text { Overall } \\
\text { rock rank }\end{array}$ \\
\hline \multirow{6}{*}{$\begin{array}{l}\text { Temperature } \\
\text { range after four } \\
\text { hours }\end{array}$} & Purple siltstone & 4 & 4 & 5 & 2 & 1 & 1 & 73 & 4 & 0 & 1 & 1 & 4 & 3 & 8 & 35 & 1 \\
\hline & Grey siltstone & 4 & 9 & 1 & 3 & 0 & 0 & 82 & 6 & 0 & 3 & 2 & 6 & 5 & 1 & 52 & 3 \\
\hline & Fossiliferous sandstone & 5 & 2 & 7 & 2 & 1 & 0 & 76 & 5 & 5 & 8 & 2 & 1 & 0 & 1 & 82 & 5 \\
\hline & Orange limestone & 1 & 0 & 1 & 5 & 6 & 4 & 41 & 2 & 3 & 0 & 9 & 3 & 1 & 1 & 66 & 4 \\
\hline & White limestone & 0 & 2 & 2 & 4 & 7 & 2 & 46 & 3 & 9 & 4 & 2 & 0 & 2 & 0 & 86 & 6 \\
\hline & Quartzite & 3 & 0 & 1 & 1 & 2 & 10 & 39 & 1 & 0 & 1 & 1 & 3 & 6 & 6 & 36 & 2 \\
\hline \multirow{6}{*}{$\begin{array}{l}\text { Change in } \\
\text { temperature } \\
\text { range over four } \\
\text { hours }\end{array}$} & Purple siltstone & 3 & 4 & 3 & 4 & 2 & 1 & 67 & 5 & 1 & 0 & 1 & 5 & 5 & 5 & 40 & 1 \\
\hline & Grey siltstone & 7 & 3 & 3 & 2 & 1 & 1 & 78 & 6 & 0 & 4 & 2 & 1 & 8 & 2 & 49 & 3 \\
\hline & Fossiliferous sandstone & 2 & 5 & 3 & 2 & 2 & 3 & 62 & 4 & 4 & 8 & 3 & 0 & 0 & 1 & 77 & 6 \\
\hline & Orange limestone & 1 & 1 & 4 & 4 & 4 & 3 & 50 & 2 & 7 & 2 & 4 & 1 & 0 & 3 & 74 & 5 \\
\hline & White limestone & 3 & 2 & 3 & 1 & 6 & 2 & 57 & 3 & 5 & 3 & 4 & 2 & 2 & 1 & 72 & 4 \\
\hline & Quartzite & 1 & 2 & 1 & 4 & 2 & 7 & 43 & 1 & 0 & 0 & 2 & 8 & 2 & 5 & 41 & 2 \\
\hline
\end{tabular}

1 
Figure 1

Mean \pm SE temperature range ( $n=6$ boulders per rock type per day).

(a) upper surfaces and (b) lower surfaces on different days (ordered by the daily maximum air temperature during sampling) during the common garden experiment. The sun or cloud symbols in panel b denote the day condition for each date sampled.
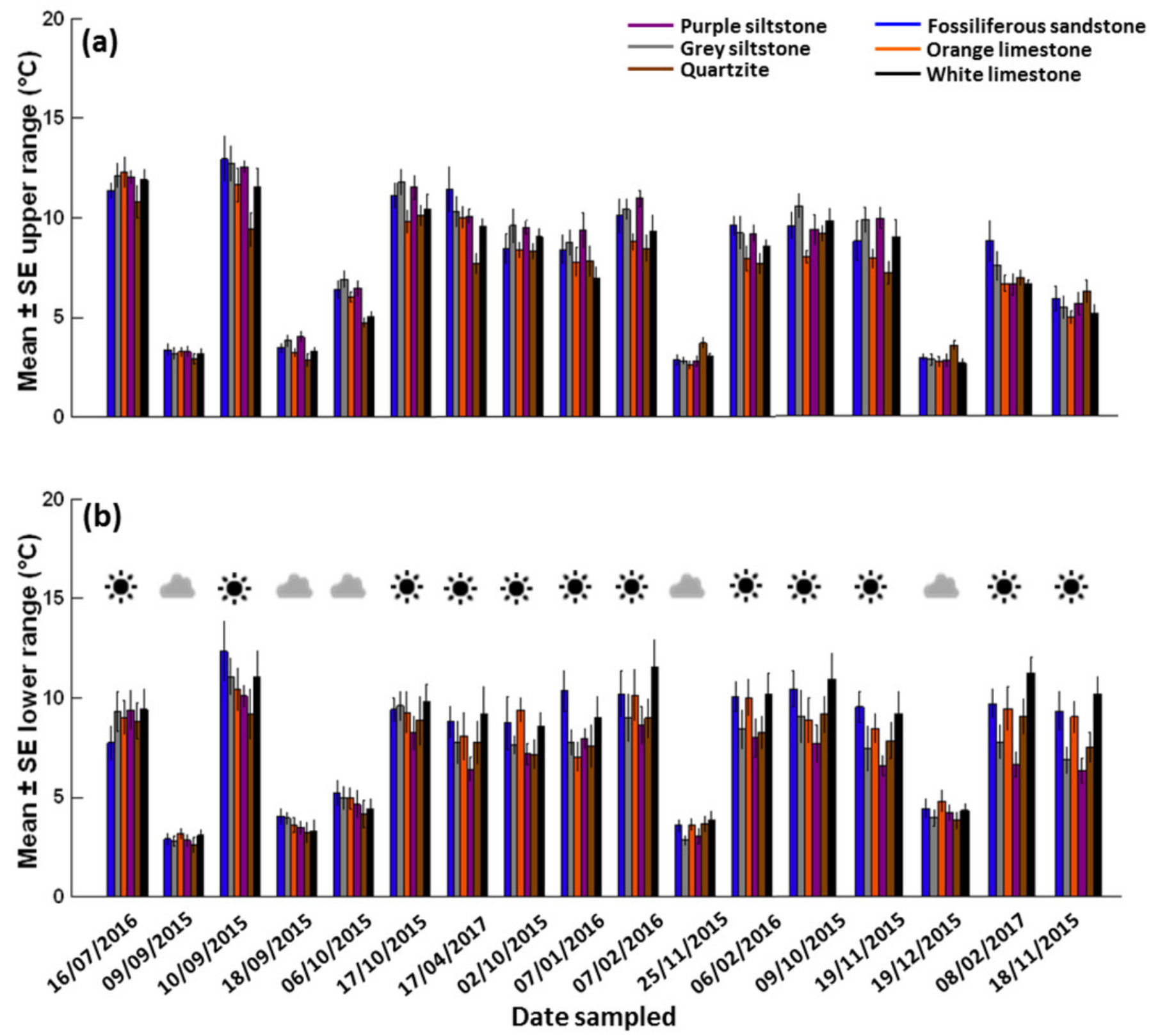


\section{Figure 2}

Thermal images showing patterns of temperature difference on the upper surfaces of boulders.

(a) grey siltstone, (b) purple siltstone, (c) quartzite, (d) fossiliferous sandstone, (e) orange limestone and (f) white limestone. Each thermal image was recorded after boulders were exposed to insolation for four hours on a sunny day (air temperature $=39{ }^{\circ} \mathrm{C}$ ). Temperature scales (at right of each image) are specific to each rock type. The red circles in panels (e) and (f) depict examples of the interruption of gradient mosaics by microhabitat features.
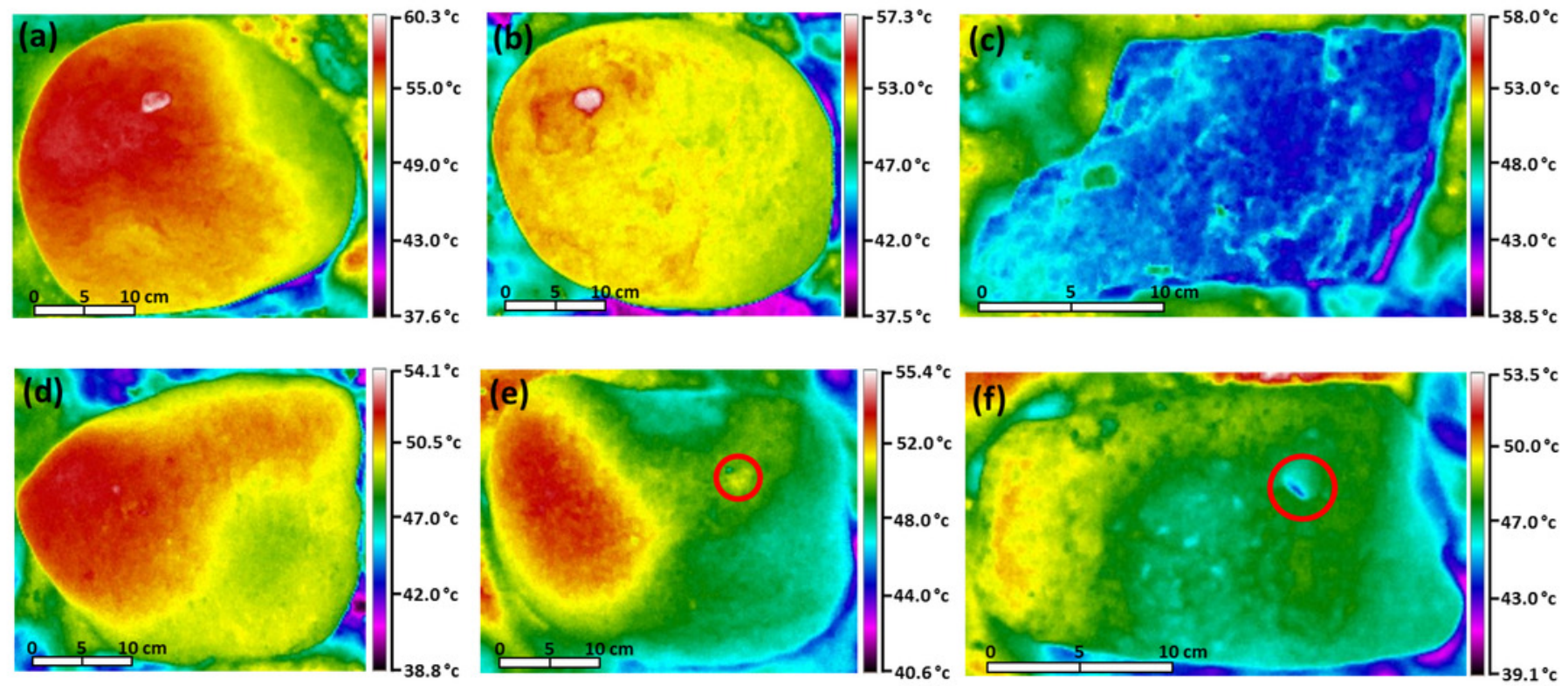


\section{Figure 3}

Thermal images showing patterns of temperature difference on boulder surfaces.

a) mosaic on the upper surface of quartzite; b) gradient on the upper surface of grey

siltstone; and c) limited heterogeneity on the upper surface of grey siltstone. Temperature scales (at right of each image) are specific to each image. The black horizontal line denotes the transect drawn on each image to quantify temperature patterns. The sun is on the left of each image.
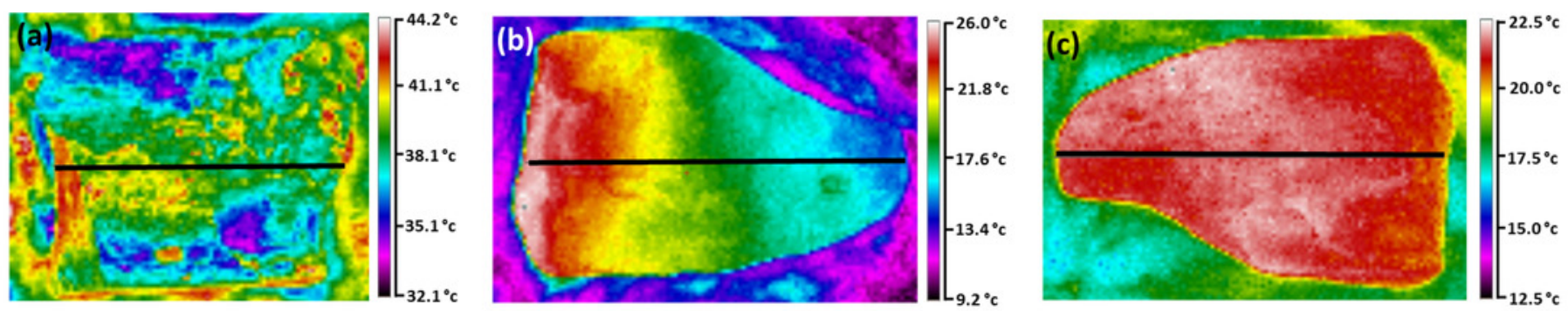
Figure 4

Scatter plots (1:1 line shown) showing the association between (a) air temperatures and mean upper maxima; (b) air temperatures and mean lower maxima; and (c) mean upper maxima and mean lower maxima after four hours for each rock type on each sunny day. 

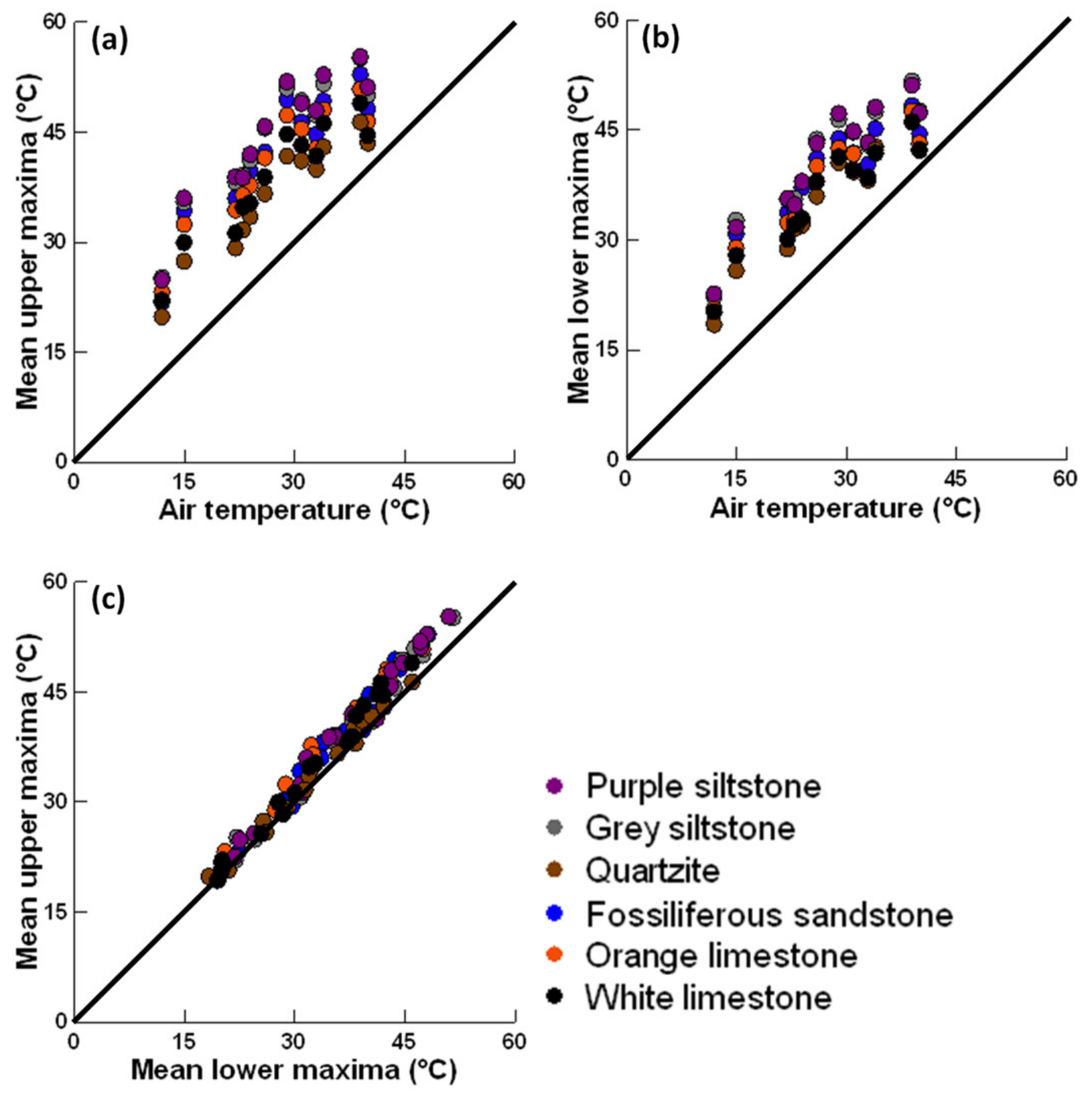

- Purple siltstone

- Grey siltstone

- Quartzite

- Fossiliferous sandstone

- Orange limestone

- White limestone

Figure 4: Scatter plots (1:1 line shown) showing the association between (a) air temperatures and mean upper maxima; (b) air temperatures and mean lower maxima; and (c) mean upper maxima and mean lower maxima after four hours for each rock type on each sunny day. 


\section{Figure 5}

Mean \pm SE (a) lower-surface maximum temperature; (b) maxima difference between upper and lower surfaces and (c) lower-surface temperature range for 6 rock types ( $n=$ 6 per rock type) over five hours of exposure to insolation on November 18, 2015.

Each $y$-axis extends to encompass the range of raw data. Please see the appendices for additional figures for the upper surfaces and other days sampled. 

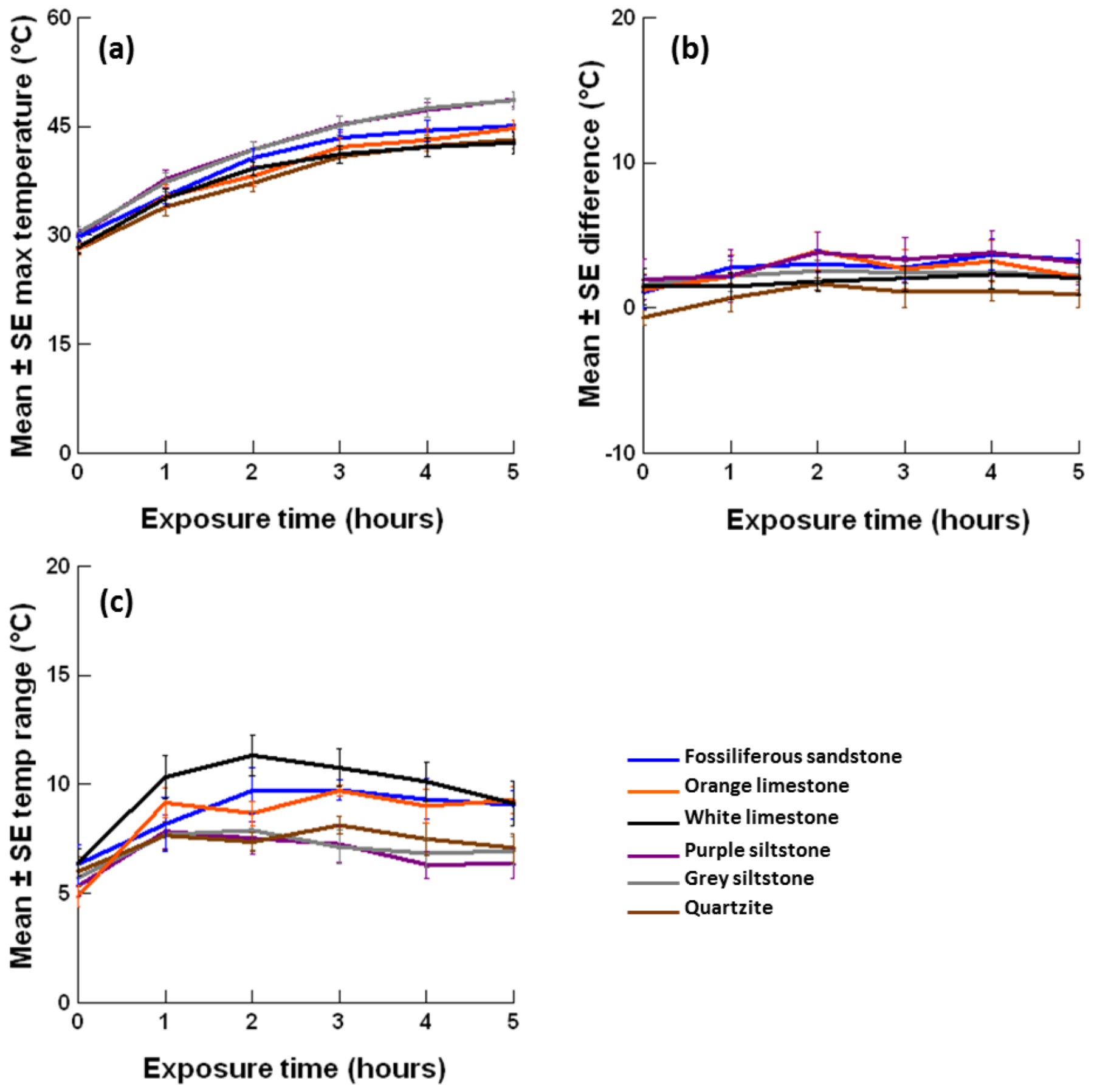


\section{Figure 6}

Constrained ordination CAP plots with vector overlay of Spearman rank correlations (for rho values $>0.8$ ) for (a) major minerals and (b) trace elements contributing to differences in mineralogy among rock types.

Each point represents a single rock sample tested. $\mathrm{CaO}=$ calcium oxide; $\mathrm{SiO}_{2}=$ silicon dioxide; $\mathrm{K}_{2} \mathrm{O}=$ potassium oxide; $\mathrm{Al}_{2} \mathrm{O}_{3}=$ aluminium oxide; $\mathrm{Yb}=$ ytterbium; $\mathrm{Y}=\mathrm{Yttrium} ; \mathrm{Br}=$ bromine; $\mathrm{Cl}=$ chlorine; $\mathrm{Zr}=$ zirconium; $\mathrm{Ce}=$ cerium; $\mathrm{Mn}=$ manganese and $\mathrm{Ga}=$ gallium .
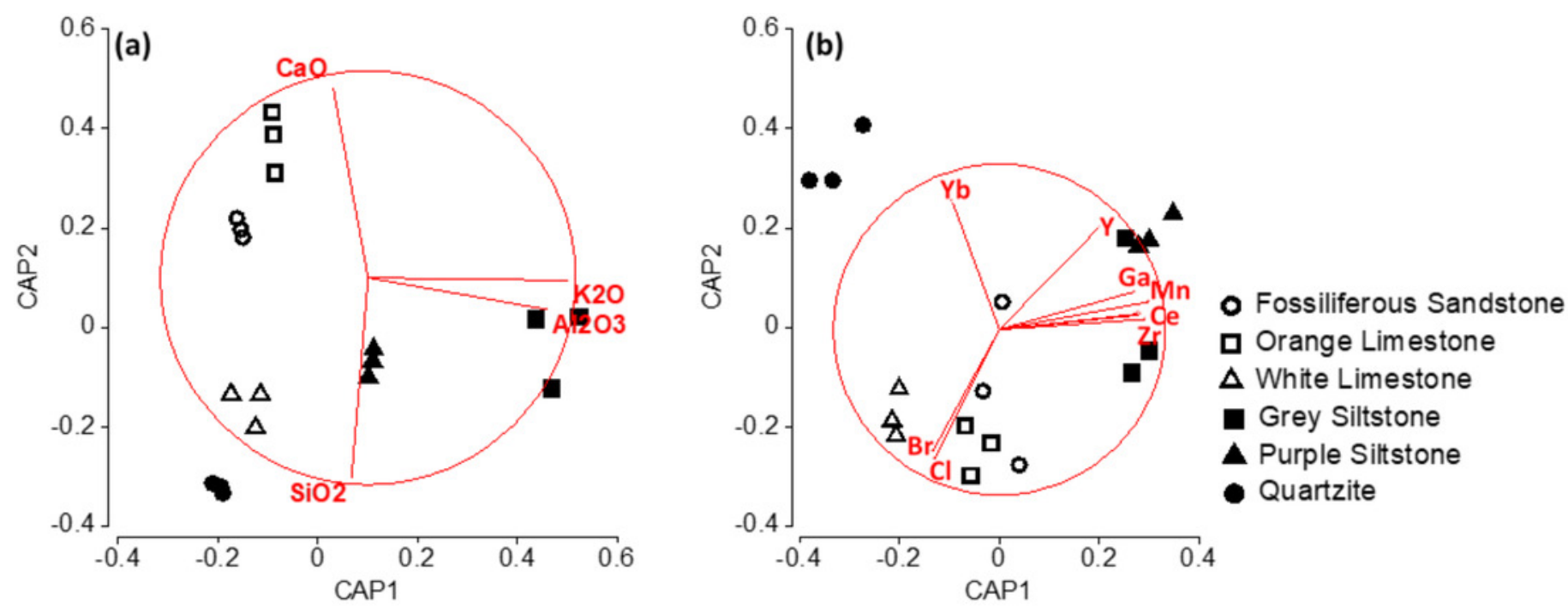